\title{
Deafness with labyrinthine aplasia, microtia, and microdontia
}

INSERM

\section{Source}

INSERM. (1999). Orphanet: an online rare disease and orphan drug data base. DeafnesS with labyrinthine aplasia, microtia, and microdontia. ORPHA:90024

Deafness with labyrinthine aplasia, microtia, and microdontia (LAMM) is a genetic transmission deafness syndrome. 